\title{
Validity and Reliability of a Tool Measuring Long-Term Employment Factors among Dental Hygienists
}

\author{
Jeong-A Yang and Soon-Ryun $\mathrm{Lim}^{1, \dagger}$ \\ Department of Dental Hygiene, The Graduate School of Namseoul University, Cheonan 31020, \\ ${ }^{1}$ Department of Dental Hygiene, Namseoul University, Cheonan 31020, Korea
}

\begin{abstract}
Dental hygienists are important members of any dental clinic. They are recognized as reflecting the dental clinic's image because they spend a lot of time with patients. The longer the dental hygienist is employed, the better the relationship with the patients and the medical service provided. The purpose of the present study was to develop a scale to measure factors of long-term employment among dental hygienists. The basic questions were constructed by analyzing tools used to measure job embeddedness and satisfaction. Forty-one questions were developed that measured organizational fit (13), interpersonal relationships (8), job satisfaction (7), duty satisfaction (6), recognition (4), and self-esteem (3). A questionnaire survey was conducted, and the responses from 297 dental hygienists in dental clinics, after the exclusion of 20 incomplete surveys, were used for the exploratory and confirmatory factor analyses. As revealed by exploratory factor analysis, long-term employment intention was composed of 7 factors consisting of 29 items after the exclusion of 12. The subsequent confirmatory factor analysis revealed 4 factors ("organizational fit," "professional identity," "job connectivity," and "interpersonal relationship") consisting of 16 items, after the exclusion of 13. Cronbach's $\alpha$ were $0806,0.836,0.700$, and 0.684 for the four factors. This study is meaningful in that it developed a long-term employment factor measurement tool that can be applied to domestic dental hygienists. Future studies will need to focus more on professional identity and job outcomes. The results of this study and future related ones could be used to improve dental hygienist's continuous service.
\end{abstract}

Key Words: Dental hygienists, Long-term employment, Reliability, Validity

\section{Introduction}

Patients who are consumers that pay for medical service demand comprehensive medical service from dental clinics $^{1}$. The service provided by dental hygienists influences the overall image of the dental clinic $^{2}$. Because they spend the most time with patients, dental hygienists are important members responsible for ${ }^{1)}$ the dental clinic's image. The longer the dental hygienist is employed, the better the relationship with the patient and the more active the medical service that is provided. However, according to a previous study, it is highly likely that the group engaged more in management and specialized work will have more turnover intentions than the group that is engaged in service and sales $^{3)}$. The median years of service of dental hygienists is 4 years. Moreover, $36.8 \%$ of dental hygienists with less than 4 years and $86 \%$ of them with more than 4 years of service reported experiencing turnover $^{4)}$. More than half $(51.6 \%)$ of them experienced turnover because of working conditions, marriage and childbirth, relationships with coworkers, and salary conditions, which was the main reason for turnover ${ }^{5}$. Now it is time to think about why they are leaving the job site and how to manage employees and encourage them to continue long-term employment at clinical sites without turnover or career interruption ${ }^{6}$.

Job satisfaction can have a positive effect on the morale of all employees by improving their interpersonal 
relationships and decreasing turnover rate, beyond the enjoyment of and positive attitude toward their jobs ${ }^{7)}$. When people are satisfied with their jobs, they become attached to their organizations ${ }^{1,8)}$. It is necessary to improve the job satisfaction of dental hygienists to prevent turnover in advance and promote work conditions that may extend the professional's life expectancy ${ }^{9)}$, as dental hygienists with long-term employment showed higher job satisfaction $^{10)}$. According to a previous study on job satisfaction, turnover intention, and relationship with dental hygienists' years of service, the following results were found: job satisfaction and turnover intention were inversely correlated, dental hygienists in the oldest age group of 36 to 40 years old who had a certain position in their current jobs had lower turnover intentions, and marital status had a significant effect on job turnover ${ }^{6}$. There was a correlation between job satisfaction factors and years of continuous employment, and autonomy factors showed high satisfaction ${ }^{5)}$. However, it was difficult to concretely identify the causal relationship between job satisfaction factors and years of service because the previous study was cross-sectional ${ }^{5)}$. Yang et al. ${ }^{11)}$ conducted in-depth interviews with dental hygienists who were employed for more than 5 years to deduce long-employment factors among domestic dental hygienists. The measurement tool developed based on the results of qualitative research consisting of the 4 factors of organization satisfaction, interpersonal relationship, professional identity, and job connectivity was used, and organization satisfaction was found to have an important effect related to long-term employment.

Although job satisfaction is closely related to long-term service, the measurement tools of job satisfaction used in previous studies define the degree of satisfaction with the job alone. Satisfaction with desires, likes or dislikes, and compensation levels are defined somewhat differently, depending on the investigator's point of view. Additionally, the intention to maintain continuous employment was based on a small number of in-depth interviews, and overlapping factors were included ${ }^{11)}$. It is difficult to conclude this is a common long-term employment factor applicable for dental hygienists. Therefore, it is necessary to develop a new standardized long-term employment factor measurement tool that complements this research.

The purpose of this study is to develop a tool used to measure long-term employment factors related to the job satisfaction of dental hygienists so this information could be used as data needed for policy development to reduce turnover and expand long-term employment. Further, it will contribute to improving the quality of dental services and enhancing the productivity of dental care.

\section{Materials and Methods}

\section{Study subjects and data collection}

From March 31 to April 13, 2018, a total of 317 dental hygienists working at dental clinics and dental hospitals were selected through convenience sampling, and a self-administered questionnaire survey was performed for a total of 2 weeks. Excluding 20 surveys that were not fully answered, a total of 297 surveys were used for the final analysis. This study was conducted with the approval of the Institutional Review Board of Namseoul University (NUSIRB-20 1710-01).

\section{Study tools}

The long-term employment factors developed by Yang's study ${ }^{12)}$ and the measurement tools to assess job embeddedness and job satisfaction used by Han et al. ${ }^{13)}$, Park and Yun ${ }^{14)}$, Yoon and Park ${ }^{15)}$, Ryu ${ }^{16)}$, and Sim and Lee $^{17)}$ were analyzed to construct the basic survey questions. The survey was composed of 53 questions contained in the 6 factors of organizational fit, interpersonal relationships, job satisfaction, duty satisfaction, recognition, and environmental satisfaction.

Organizational fit comprised 12 question covering such things as "internal education program," "benefits of longterm employment," and "flexible work hours." Interpersonal relationship was composed of 8 questions covering such things as "satisfaction with the director's character," "good relationship among staff," and "communication with staff." Job satisfaction was composed of 9 questions covering such things as "job responsibility," "sincerity of heart," and "sense of duty as a healthcare professional." Duty satisfaction was composed of 9 questions covering such things as "recognition from 
people," "senior's recognition of difficulties," and "satisfaction with authority responsibility." Environment satisfaction was composed of 6 questions covering such things as "convenient commute" and "satisfaction with the dental clinic's size." In total, the questionnaire survey was composed of 53 questions.

The basic questions deduced from a literature review were reviewed by an expert group to verify whether they could measure the long-term employment of dental hygienists or if there were additional questions that needed to be added. This group consisted of a total of 14 experts, including 4 dental hygienics professors, 3 students in a dental hygienics doctoral program, and 7 dental hygienists with more than 5 years of continuous service. Each question was rated from 1 point for "very inappropriate" to 4 points for "very appropriate," and a Content Validity Index (CVI) was computed to calculate the ratio of respondents who responded with answers of 3 or 4 points for each question. As a result, 12 questions with a CVI below 0.6 were excluded, and 3 questions on self-esteem were added to reflect the expert group's comments. There was a total of 41 questions consisting of 13 on organizational fit, 8 on interpersonal relationships, 7 on job satisfaction, 6 on duty satisfaction, 4 on recognition, and 3 on self-esteem.

The finalized questions were scored on a 5-point Likert scale, from 1 point for "strongly disagree" to 5 points for "strongly agree." Higher scores indicated more positive long-term employment factors.

\section{Data analysis}

Data were analyzed using IBM SPSS Statistics ver. 20.0 (IBM Co., Armonk, NY, USA) and IBM SPSS AMOS 18.0 (IBM Co.). General characteristics were analyzed as frequencies and percentages. In order to confirm construct validity, exploratory factors analysis was performed. For the exploratory factors analysis, a factor extraction method was used to analyze the principal components. After computing the KOM value, factor analysis using varimax rotation was performed. Confirmatory factor analysis was also performed to confirm each constructing factor's influence, validate the goodness of fit of the model, and verify chi-square values representing validity. Correlations were verified through the average extracted variance and discriminant validity.

\section{Results}

\section{General characteristics}

Most of the respondents $(287,96.6 \%)$ were women, and the most common age group was between 26 and 30 years old of age $(124,41.8 \%)$ people. There were 182 dental hygienists $(61.3 \%)$ with an associate's degree; 115 (38.7\%) were unmarried, and $182(61.3 \%)$ were married. The most common career experience category was more than 10 years $(97,32.7 \%)$. Regarding years of service within their current clinical situation, most respondents fit into the 1 to 2 years category $(109,36.7 \%)$. Moreover, 56 (18.9\%) had been employed for 3 to 5 years. Sixty-two respondents (20.9\%) had no experience of turnover (Table 1 ).

Table 1. Subject Characteristics

\begin{tabular}{|c|c|c|}
\hline Characteristic & Classification & $\mathrm{n}(\%)$ \\
\hline \multirow[t]{2}{*}{ Gender } & Male & $10(3.4)$ \\
\hline & Female & $287(96.6)$ \\
\hline \multirow[t]{4}{*}{ Age (y) } & $\leq 25$ & $44(14.8)$ \\
\hline & $26 \sim 30$ & $124(41.8)$ \\
\hline & $31 \sim 35$ & $58(19.5)$ \\
\hline & $\geq 36$ & $71(23.9)$ \\
\hline \multirow[t]{3}{*}{ Level of education } & Associate's degree & $182(61.3)$ \\
\hline & Bachelor's degree & $97(32.7)$ \\
\hline & Master's degree or above & $18(6.1)$ \\
\hline \multirow[t]{2}{*}{ Marriage } & Unmarried & $115(38.7)$ \\
\hline & Married & $182(61.3)$ \\
\hline \multirow[t]{5}{*}{ Total career (y) } & $<1$ & $23(7.7)$ \\
\hline & $1 \sim 2$ & $37(12.5)$ \\
\hline & $3 \sim 5$ & $60(20.2)$ \\
\hline & $6 \sim 10$ & $80(26.9)$ \\
\hline & $\geq 10$ & $97(32.7)$ \\
\hline \multirow[t]{5}{*}{ Years of service $(y)$} & $<1$ & $84(28.3)$ \\
\hline & $1 \sim 2$ & $109(36.7)$ \\
\hline & $3 \sim 5$ & $56(18.9)$ \\
\hline & $6 \sim 10$ & $30(10.1)$ \\
\hline & $\geq 10$ & $18(6.1)$ \\
\hline Turnover & 1 & $69(23.2)$ \\
\hline \multirow[t]{3}{*}{ experience } & 2 & $57(19.2)$ \\
\hline & $\geq 3$ & $109(36.7)$ \\
\hline & No & $62(20.9)$ \\
\hline Total & & $297(100)$ \\
\hline
\end{tabular}




\section{Verification of validity and reliability}

\section{1) Exploratory factor analysis}

Repeated exploratory factor analysis was performed with the 41 survey questions. Before the factor analysis was conducted, goodness of fit was measured. In this study, Kaiser-Meyer-Olkin was 0.912, and the chi-square value based on Bartlett's test for sphericity was 4,017.615 $(\mathrm{p}<0.001)$. Therefore, questions used in this study satisfied the factor analysis criteria. Principal component analysis was used for the model of factor analysis, and varimax rotation, one of the orthogonal rotations, was performed. Twelve questions with a factor loading less than 0.5 were removed. "Fits with the work I desire" was a question with a factor loading less than 0.5 , but it was included in the final set of questions as it was considered important to this study. Thus, 7 factors with 29 questions were constructed (Table 2). The removed questions were those pertaining to "job responsibility," "benefits of long-term employment," "sincere heart," “childbirth/

Table 2. Factor Analysis Regarding Long-Term Employment

\begin{tabular}{|c|c|c|c|c|c|c|c|c|}
\hline Item & Factor 1 & Factor 2 & Factor 3 & Factor 4 & Factor 5 & Factor 6 & Factor 7 & Communalities \\
\hline A reasonable reward (A32) & 0.775 & 0.247 & 0.135 & 0.051 & 0.083 & 0.074 & 0.107 & 0.706 \\
\hline Satisfaction with the welfare benefits (A16) & 0.725 & 0.235 & 0.179 & 0.136 & 0.002 & -0.059 & 0.174 & 0.665 \\
\hline $\begin{array}{l}\text { Accept a suggestion of unreasonable at work } \\
\text { (A34) }\end{array}$ & 0.693 & 0.112 & 0.256 & 0.107 & 0.123 & 0.146 & 0.185 & 0.640 \\
\hline Professional growth potential (A33) & 0.581 & 0.205 & 0.291 & -0.069 & 0.072 & 0.247 & 0.331 & 0.645 \\
\hline Satisfaction with the decisions of dentist (A22) & 0.549 & 0.143 & 0.433 & 0.049 & 0.178 & -0.021 & 0.129 & 0.560 \\
\hline Problem is solved fairly (A39) & 0.497 & 0.032 & 0.369 & 0.096 & 0.413 & 0.277 & -0.041 & 0.642 \\
\hline Pride and self-confidence in working (A19) & 0.145 & 0.79 & 0.058 & 0.084 & 0.098 & 0.256 & 0.065 & 0.735 \\
\hline Being proud of telling my work (A11) & 0.234 & 0.775 & -0.023 & 0.167 & 0.041 & 0.15 & 0.05 & 0.710 \\
\hline Prospect is bright socially and economically (A5) & 0.13 & 0.721 & 0.163 & 0.231 & 0.117 & -0.033 & 0.133 & 0.650 \\
\hline Being pleased and worth to work (A6) & 0.216 & 0.659 & 0.279 & 0.143 & 0.112 & 0.159 & 0.08 & 0.624 \\
\hline Trusting the treatment abilities of dentists (A35) & 0.177 & 0.054 & 0.802 & 0.004 & -0.053 & 0.119 & 0.101 & 0.704 \\
\hline The dentists' ethical personality (A2) & 0.292 & 0.033 & 0.743 & 0.011 & 0.093 & 0.004 & 0.082 & 0.653 \\
\hline $\begin{array}{l}\text { Dentist respects the occupation of dental } \\
\text { hygienists (A18) }\end{array}$ & 0.394 & 0.272 & 0.533 & 0.142 & 0.139 & 0.035 & 0.175 & 0.584 \\
\hline Smooth cooperation with a dentist (A23) & 0.144 & 0.227 & 0.532 & 0.384 & 0.239 & 0.035 & 0.155 & 0.585 \\
\hline My value matches the value of dental clinic (A36) & 0.487 & 0.098 & 0.532 & 0.036 & 0.127 & 0.288 & 0.007 & 0.630 \\
\hline $\begin{array}{l}\text { The dentist's request is consistent with the work } \\
\text { I want to do (A25) }\end{array}$ & 0.161 & 0.295 & 0.322 & 0.286 & 0.306 & 0.264 & 0.031 & 0.462 \\
\hline Being good at work (A4) & -0.037 & 0.091 & 0.135 & 0.836 & 0.13 & 0.023 & -0.019 & 0.745 \\
\hline Having a long career (A14) & 0.147 & 0.143 & -0.15 & 0.773 & -0.04 & 0.05 & -0.02 & 0.667 \\
\hline I'm good at skills and ability (A24) & 0.094 & 0.318 & 0.127 & 0.692 & 0.117 & 0.291 & 0.162 & 0.730 \\
\hline $\begin{array}{l}\text { My work and position in the clinic are important } \\
\text { (A37) }\end{array}$ & 0.113 & 0.177 & 0.284 & 0.52 & 0.266 & 0.302 & 0.063 & 0.562 \\
\hline Communicate with all members (A29) & 0.144 & 0.106 & -0.105 & 0.053 & 0.835 & 0.118 & 0.054 & 0.760 \\
\hline Having good relationship with all members (A8) & 0.032 & 0.138 & 0.272 & 0.148 & 0.753 & -0.067 & 0.149 & 0.709 \\
\hline Solving problems with all members (A38) & 0.382 & 0.037 & 0.243 & 0.224 & 0.467 & 0.374 & -0.072 & 0.620 \\
\hline $\begin{array}{l}\text { Challenging the professionalism of dental } \\
\text { hygienist (A40) }\end{array}$ & 0.065 & 0.092 & 0.116 & 0.18 & 0.088 & 0.715 & 0.163 & 0.604 \\
\hline Sense of duty (A30) & 0.085 & 0.524 & 0.003 & 0.15 & 0.048 & 0.619 & 0.055 & 0.692 \\
\hline A sense of social contribution (A31) & 0.132 & 0.414 & 0.057 & 0.043 & 0.016 & 0.559 & 0.16 & 0.532 \\
\hline Having its own educational program (A1) & 0.059 & 0.075 & 0.17 & 0.005 & 0.049 & 0.108 & 0.841 & 0.759 \\
\hline Provides support for educational programs (A28) & 0.418 & 0.082 & -0.02 & 0.153 & -0.024 & 0.142 & 0.633 & 0.626 \\
\hline Giving an opportunity of promotion (A21) & 0.352 & 0.2 & 0.173 & -0.022 & 0.228 & 0.095 & 0.59 & 0.603 \\
\hline Eigen value & 3.727 & 3.298 & 3.137 & 2.610 & 2.116 & 2.037 & 1.879 & \\
\hline Ratio of total variance explained (\%) & 12.853 & 11.371 & 10.818 & 9.000 & 7.296 & 7.024 & 6.481 & \\
\hline Cumulative ratio (\%) & 12.853 & 24.224 & 35.042 & 44.042 & 51.338 & 58.361 & 64.842 & \\
\hline
\end{tabular}


Table 3. Modification Model Fit Index

\begin{tabular}{cccccccccccc}
\hline & p-value & CMIN/DF & GFI & AGFI & RMR & RMSEA & NFI & CFI & IFI & TLI \\
\hline Model & 0.000 & 3.119 & 0.884 & 0.840 & 0.059 & 0.085 & 0.844 & 0.887 & 0.888 & 0.861 \\
Fit & $>0.05$ & $<3$ & $\geq 0.9$ & $\geq 0.9$ & $\leq 0.05$ & $\leq 0.05$ & $\geq 0.9$ & $\geq 0.9$ & $\geq 0.9$ & $\geq 0.9$ \\
\hline
\end{tabular}

CMIN: minimum chi-square, DF: degree of freedom, GFI: goodness of fit index, AGFI: adjusted GFI, RMR: root mean square residual, RMSEA: root mean squared error of approximation, NFI: normed fit index, CFI: comparative fit index, IFI: incremental fit index, TLI: Turker-Lewis index.

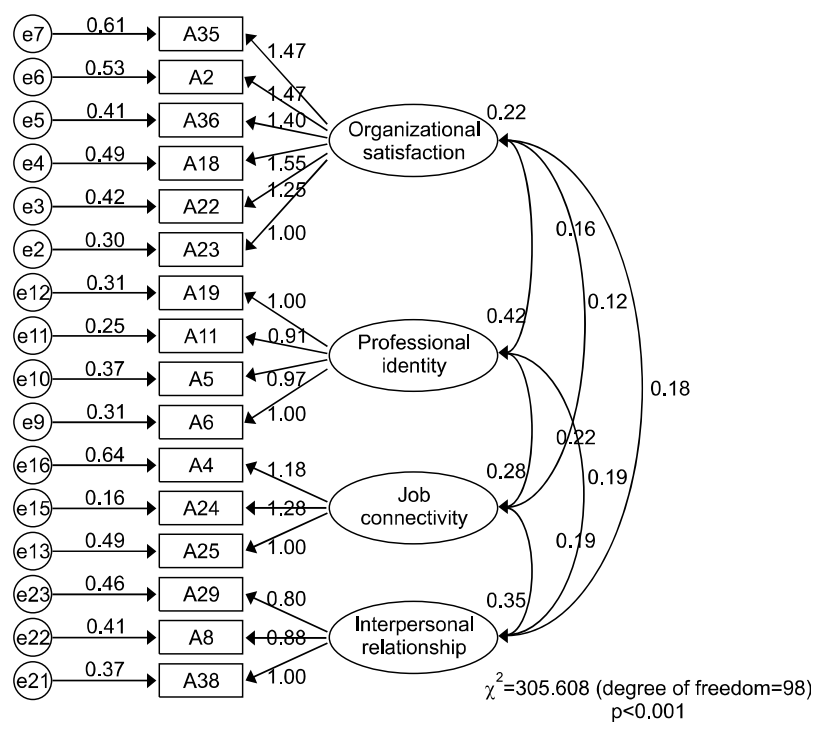

Fig. 1. Model of confirmatory factor analysis. childcare leave," "respect for members," "growth if immature," "guaranteed employment stability," "fair work distribution," "presence of autonomy and independence," "recognition of difficulties by seniors," "satisfaction with authority responsibility," and "flexible work hours."

\section{2) Confirmatory factor analysis}

Through confirmatory factor analysis, 13 questions with a standardized factor loading of less than 0.5 were removed, and a total of 4 factors and 16 questions were finalized. The questions that were removed regarded the following: "sense of duty," "having a long career," "importance of work position," "flexible work hours," "satisfaction with welfare benefits," "a reasonable reward," "acceptance of suggestions," "internal education program," "support for external education," "promotion opportunities," "sincerity of heart," "job responsibility," and "respect for

Table 4. Result of Multiple Regression Analysis

\begin{tabular}{|c|c|c|c|c|c|c|}
\hline Construct & Item & Estimate & $\begin{array}{c}\text { Standardized } \\
\text { regression weight }\end{array}$ & $\begin{array}{l}\text { Critical } \\
\text { ratio }\end{array}$ & p-value & $\begin{array}{l}\text { Construct } \\
\text { reliability }\end{array}$ \\
\hline \multirow[t]{6}{*}{$\mathrm{F} 1$} & A23 & 1.000 & 0.652 & & & 0.859 \\
\hline & A22 & 1.254 & 0.671 & 9.686 & $<0.001$ & \\
\hline & A18 & 1.548 & 0.720 & 10.246 & $<0.001$ & \\
\hline & A36 & 1.396 & 0.714 & 10.182 & $<0.001$ & \\
\hline & $\mathrm{A} 2$ & 1.470 & 0.686 & 9.865 & $<0.001$ & \\
\hline & A35 & 1.473 & 0.662 & 9.586 & $<0.001$ & \\
\hline \multirow[t]{4}{*}{$\mathrm{F} 2$} & A6 & 1.000 & 0.757 & & & 0.879 \\
\hline & A5 & 0.969 & 0.721 & 11.754 & $<0.001$ & \\
\hline & A11 & 0.907 & 0.762 & 12.397 & $<0.001$ & \\
\hline & A19 & 1.001 & 0.762 & 12.393 & $<0.001$ & \\
\hline \multirow[t]{3}{*}{ F3 } & $\mathrm{A} 25$ & 1.000 & 0.602 & & & 0.770 \\
\hline & A24 & 1.279 & 0.864 & 9.459 & $<0.001$ & \\
\hline & A4 & 1.184 & 0.617 & 8.318 & $<0.001$ & 0.744 \\
\hline \multirow[t]{3}{*}{ F4 } & A38 & 1.000 & 0.700 & & & \\
\hline & A 8 & 0.880 & 0.631 & 8.241 & $<0.001$ & \\
\hline & A29 & 0.798 & 0.573 & 7.705 & $<0.001$ & \\
\hline
\end{tabular}

F1: organization satisfaction, F2: professional identity, F3: job connectivity, F4: interpersonal relationship. 
Table 5. Correlation Coefficients among the Variables

\begin{tabular}{ccccc}
\hline Characteristic & F1 & F2 & F3 & F4 \\
\hline F1 & 1 & & & \\
F2 & 0.535 & 1 & & \\
F3 & 0.663 & 0.651 & 1 & \\
F4 & 0.663 & 0.488 & 0.603 & 1 \\
AVE & 0.504 & 0.645 & 0.535 & 0.494 \\
\hline
\end{tabular}

F1: organization satisfaction, F2: professional identity, F3: job connectivity, F4: interpersonal relationship, AVE: average variance extracted.

members." The remaining 4 factors were named "organization satisfaction," "professional identity," "job connectivity," and "interpersonal relationships." The results showed significance with $\chi^{2} \mathrm{p}<0.001$. Other values included minimum chi-square/degree of freedom $(\mathrm{CMIN} / \mathrm{DF})=3.119$, goodness of fit index $(\mathrm{GFI})=0.884$, adjusted GFI (AGFI) $=0.840$, root mean square residual $(R M R)=0.059$, root mean squared error of approximation $($ RMSEA $)=0.085$, normed fit index $(\mathrm{NFI})=0.844$, comparative fit index $(\mathrm{CFI})=0.887$, incremental fit index $(\mathrm{IFI})=0.888$, and Turker-Lewis index $(\mathrm{TLI})=0.861$ (Table 3, Fig. 1).

All 4 factors confirmed construct reliability (CR) by meeting the standard of being greater than 0.7 (Table 4).

Average variance extracted (AVE) signifies the correlation of measurement variables for each potential factor. The AVEs were $0.504,0.645$, and 0.535 for factors 1, 2, and 3, which exceeded the standard. On the other hand, the AVE for factor 4 was 0.494; however, since this was near the standard, internal consistency was confirmed (Table 5). To validate the discriminant validity, the AVE values for each of the four factors and the squared correlations between the factors were compared. The squares of the correlations between all potential factors were between $0.238 \sim 0.439$, and because they were all smaller than 0.494 , the discriminant validity between the 4 factors' CR was confirmed.

\section{3) Reliability}

Upon verifying the Cronbach's $\alpha$ for all 16 items, the results were $0.806,0.836,0.700$, and 0.684 , with high internal consistency (Table 6).
Table 6. Reliability of the Tool Used to Measure Long-Term Employment Factors

\begin{tabular}{lcc}
\hline \multicolumn{1}{c}{ Variable } & Item & Cronbach's $\alpha$ \\
\hline Organizational satisfaction & 6 & 0.806 \\
Professional identity & 4 & 0.836 \\
Job connectivity & 3 & 0.700 \\
Interpersonal relationship & 3 & 0.684 \\
\hline
\end{tabular}

\section{Discussion}

Unlike people who work within the general workforce, those with specialized professions continue to work in their specialities unless they change fields. Therefore, professional career commitment is an important variable related to performance among individuals and organizations ${ }^{18)}$. The number of dental hygienists in dental clinics has been gradually increasing, but there are still many small dental hospitals that cannot hire dental hygienists ${ }^{6}$. The establishment of dental hygienist jobs is the basis for providing stable dental care services to the public. Once a system that recognizes the expertise and proficiency of long-term employees is established, making the most of it will have a positive impact on the management of dental clinics and hospitals ${ }^{17)}$.

This study was based on a study by Yang et al. ${ }^{11)}$ and a related literature review to develop a measurement tool, for which there was a total of 53 basic questions (12 on organizational fit, 8 on interpersonal relationships, 9 on job satisfaction, 9 on duty satisfaction, 9 on recognition, and 6 on environmental satisfaction). Based on an expert group's review, 12 questions with a CVI below 0.6 were excluded, while 1 factor and 3 questions were added. This resulted in a total of 41 questions, including 13 on organizational fit, 8 on interpersonal relationships, 7 on job satisfaction, 6 on duty satisfaction, 4 on recognition, and 3 on self-esteem, being selected. Exploratory factors analysis was performed to construct 7 factors and 29 questions. Through confirmatory factor analysis, 13 questions were removed; thus, 16 questions on 4 factors remained.

Factor 1 was on organizational satisfaction, which was the result of combining satisfaction with the organization and with superiors and interpersonal relationships. Dental hygienists who have affection or loyalty toward an 
organization and recognize the workplace's problems as their own are better able to maximize the achievement and performance of dental medical institutions through enhancing patient satisfaction, as well as reducing turnover intentions ${ }^{19)}$. Additionally, the interpersonal relationships consisted of satisfaction with superiors and coworkers. However, satisfaction with the superior was combined with organizational satisfaction, and relationships with coworkers comprised one factor. The perception of the superior seems to be perceived in relation to the organization rather than interpersonal relationships. In terms of the long-term employment of dental hygienists, it is important to make efforts to improve dentists' treatment abilities, as well as their efforts to respect employees.

Factor 2 is composed of professional identity as a dental hygienist ${ }^{12)}$. A program is needed that can continuously motivate the dental hygienists to work and improve their professional capacities ${ }^{20}$. Positive occupational view is believed to influence duty satisfaction, and this shows the importance of education and a positive organizational culture that can cultivate an active and positive mind in order for dental hygienists to fulfill their roles as professional workers ${ }^{21)}$. It is necessary to introduce a system that allows dental hygienists to freely perform within the scope of their work so they can improve their identities.

Factor 3 is job connectivity, which includes details concerning the work ${ }^{11)}$. This aligns with the results of a previous study that found that the higher the person-duty fit, the higher the interpersonal trust and organizational trust. This would, in turn, lead to higher duty satisfaction $^{22)}$. Therefore, open communication is necessary for dental hygienists to understand what they want and feel pride in their work through appropriate compensation.

Factor 4 is composed of interpersonal relationships. As the study by Lee showed, the interpersonal relationship factor had the highest satisfaction ${ }^{10)}$. It is an important factor in the construction of long-term employment. This is a result showing that work interactions are necessary for dental hygienists to recognize their work as a team-linked task, not a personally separated task ${ }^{21)}$. Since good interpersonal relationships in the workplace have a significant effect on productivity as much as do work conditions and salary levels, good quality medical services can be achieved when interdependent work is performed by maintaining good relationships with coworkers within the workplace ${ }^{21)}$.

This study is meaningful in that it developed a long-term employment factor measurement tool applicable to domestic dental hygienists. Further studies are needed to evaluate the usefulness of the measurement tool and to identify the effects of long-term employment on factors such as professionalism and duties.

\section{References}

1. Lee SM, Kim SH: Effects of professionalism and selfefficacy on the job satisfaction of dental hygienists using the structural equation model. J Den Hyg Sci 12: 271-277, 2012.

2. Lee CS, Lim SH, Han JH: The effect of the intramural marketing activities in dental hygienist' on job satisfaction and turnover intention in dental hygienist. J Den Hyg Sci 12: 15-22, 2012.

3. Jeong YK, Han YS: The effect of family care program in workplace on turnover intention and work-family interaction for married working women. J Korean Fam Resour Manag Assoc 20: 61-87, 2016.

4. Kim HJ, Kim YJ, Kim MH: A study of factors related to job satisfaction affecting service year: a dental hygienist in Seoul. J Den Hyg Sci 14: 510-515, 2014. https://doi.org/10.17135/jdhs.2014.14.4.510

5. Go EJ, Cho YH, Yoon HS: Relative factors intent to leave for dental hygienists. J Korean Acad Dent Hyg Educ 9: 644-658, 2009.

6. Yoon MS: Suggestions for settlement stable employment culture of dental hygienist. J Dent Hyg Sci 17: 463-471, 2017. https://doi.org/10.17135/jdhs.2017.17.6.463

7. Lee BH, Kim JS: The relationship between coaching behaviors of dental managers, job satisfaction and job performance of dental hygienists. Korean J Health Serv Manag 6: 121-130, 2012. https://doi.org/10.12811/kshsm.2012.6.4.121

8. Lee YS, Jang JH, Moon AE: The effects of emotional labor and stress on job satisfaction in oral health professional. $\mathrm{J}$ Korean Soc Dent Hyg 11: 823-831, 2011.

9. Park JH: Burnout and job satisfaction among dental 
hygienists in some legions. J Korean Soc Dent Hyg 9: 569-579, 2009.

10. Lee ML, Lee HC: The effect influence of job satisfaction on turnover intention in dental hygienists. J Korean Soc Dent Hyg 16: 303-311, 2016. https://doi.org/10.13065/jksdh.2016.16.02.303

11. Yang JA, Lim SR, Cho YS: Development of scale of long-term employment intention for dental hygienist. J Korean Soc Dent Hyg 17: 1025-1035, 2017. https://doi.org/10.13065/jksdh.2017.17.06.1025

12. Yang JA: Qualitative study on dental hygienist intention to stay at current work in dental clinics. Unpublished master's thesis, Namseoul University, Cheonan, 2016.

13. Han YS, Moon HJ, Cho YS: Reliability and validity of the Korean version of job embeddedness for measurement tool of dental hygienist. J Dent Hyg Sci 16: 18-25, 2016. https://doi.org/10.17135/jdhs.2016.16.1.18

14. Park SA, Yun SN: Measurement of job satisfaction of nurses and health workers in health centers. J Korean Acad Nurs 22: 316-324, 1992. https://doi.org/10.4040/jnas.1992.22.3.316

15. Yoon KS, Park SA: Development and validation of an instrument to measure the job satisfaction of perioperative nurses. J Korean Clin Nurs Res 15: 93-106, 2009.

16. Ryu SH: Influence of job characteristics and job satisfaction of hospital staff on organizational citizenship behavior.
Unpublished master's thesis, Chonbuk National University, Jeonju, 2004.

17. Sim HS, Lee HN: A study on factors affecting the job satisfaction of dental hygienists in part areas. J Korean Soc Dent Hyg 10: 555-565, 2010.

18. Lee CW: The effect of health care professional employees' person-environment fit on career commitment. Korean Ind Econ Res 25: 2549-2573, 2012.

19. Choi HN, Lim SR, Cho YS: Factors associated with turnover intention of dental hygienists. J Korean Soc Dent Hyg 10: 973-981, 2010.

20. Kim JH, Han SJ: The effect of self-leadership on organizational effectiveness and job performance in dental hygienist. J Korean Soc Dent Hyg 16: 1079-1092, 2016. https://doi.org/10.13065/jksdh.2016.16.06.1079

21. Shin MW. Kim YS: The effects subjective fatigue symptoms to job satisfaction in Daejon city and south Chungcheong province of dental hygienists. J Korean Soc Dent Hyg 8: 73-91, 2008.

22. Park SM, Kim MY, Kim MJ: Exploring the impacts of person-job fit (P-J Fit) and person-organization fit (P-O Fit) on organizational outcomes: with a focus on the mediating effects of interpersonal and organizational trust. Korean Public Adm Q 25: 557-594, 2013. 